\title{
Environmental sustainability and economic development in Russian regions: spatial analysis
}

\author{
Arina Suvorova ${ }^{1, *}$ \\ ${ }^{1}$ Institute of Economics of the Ural Branch of RAS, 29, Moskovskaya str., 620014, Yekaterinburg, \\ Russia
}

\begin{abstract}
Environmental degradation and increasing risks to regional ecosystems seriously impede the progress towards sustainable development goals. This study is aimed at investigating the spatial aspect of this problem by focusing on the case of Russia, in particular the environmental aspects of the country's spatial organization. Methodologically, the study relies on spatial analysis methods (spatial modelling and mapping) and the official statistical data. As a result, we have identified heavily polluted locations that jeopardize sustainable development efforts on the national level: as these locations are situated in close proximity to each other and share a strong spatial correlation, their combined impact far exceeds that of isolated territories. It was found that Siberia is the largest zone of concentration of air pollution hotspots, where high levels of air pollution are not compensated for by these regions' outstanding economic performance. Our findings have shown that the patterns of the country's economic and environmental spatial organization do not always coincide. In other words, the regions with booming economies are not always the same regions whose manufacturing sector puts the heaviest pressure on the environment. This can point to the fact that the link between economic activities and environmental pressures is now weakening.
\end{abstract}

\section{Introduction}

Global problems such as the growing economic and social injustice place the idea of sustainable development at the forefront of discussions on the future of modern society. The concept of sustainable development is informed by the idea of harmony in the human-nature relationship and the relationships between people, of the need to balance economic, social, and environmental policies and goals [1]. These ideas are constantly enriched with new meanings and aspects and do not lose their value with time.

The idea of sustainable development goes back to the 1970s and brings together social equity, environmental protection, and economic growth. Among the many milestone events, which marked the crystallization of this concept, were the publication of the seminal work 'Limits to Growth' in 1972 by Donella and Dennis Meadows and their co-authors and the UN Environment Programme (https://www.unep.org), which put forward the idea that ignoring

*Corresponding author: av_suvorova_av@mail.ru 
environmental issues would prevent socio-economic systems from realizing their full growth potential. The concept of sustainable development was more precisely defined in 1987 in the report 'Our Common Future' of the Brundtland Commission (https://sustainabledevelopment.un.org/content/documents/5987our-common-future.pdf).

The report described the type of development which 'meets the needs of the present without compromising the ability of future generations to meet their own needs' (it is this definition of sustainable development that is now considered classical). The UN's Sustainable Development Agenda until 2030 describes 17 sustainable development goals (https://www.un.org/sustainabledevelopment), such environmental conservation, eradication of poverty, climate action, economic growth, good health and well-being, quality education, and reduction of inequalities in access to resources. Although certain progress has been achieved in some of the above-mentioned goals, most countries are still struggling to make headway. What is more, in many spheres, the situation is getting worse: for instance, UN experts have reported increasing deterioration of the environment and the emergence of new environmental threats.

A large body of research literature is devoted to the identification of the parameters that have the strongest impact on the environment. These studies highlight the objectives reasons behind the environmental issues such as the direct correlation between the level of atmospheric emissions and industrialization [3], urbanization [4], and economic growth [5, 6]. In different countries or regions, however, these correlations can be different due to their industrial specialization, level of technological development, the degree of environmental consciousness of industrial enterprises and so on. Therefore, the research focusing on specific national socio-economic systems (e.g. Asia, especially China [7, 8]] or Arab states [6, 9]) is particularly relevant. Organization of environmental space is another question worthy of discussion: even on the national scale such space is never homogeneous and, therefore, it is important to explore how environmentally damaged zones are localized and to identify the specific types of threats to the prosperity of regions (these threats are usually associated with the concentration of pollution hotspots, whose combined impact on the surrounding territories is stronger than their individual impact).

Our study aims to analyze the environmental aspects of spatial organization in Russia. To this end, we intend to identify those special elements where the scale of pollution raises most concern. Moreover, we are going to show the connections between the organization patterns of the country's environmental and economic space.

\section{Materials and methods}

Our study focuses on the case of the Russian Federation - a country where matters of environmental degradation and damage have been left neglected for a long time and which is now facing the urgent need to reduce the anthropogenic pressure on the environment and develop the 'green' economy [10]. Since environment is a complex, multi-faceted research topic, in our study we are going to concentrate on only one of its aspects - air pollution from stationary sources such as power plants and manufacturing facilities. It should be noted that, in our research, we rely predominantly on the regional- rather than national-level data.

The above considerations have determined our choice of indicators, which include the volume of atmospheric emissions from stationary sources (release of chemicals, vapours, and dust by enterprises using air pollution control equipment; other air pollution contributors devoid of such equipment, both stationary and mobile) and gross regional product (GRP) (an integral characteristic of this or that territory's economic performance). The combination of these two parameters - atmospheric emissions and value added - provides us with an effective indicator to measure the progress towards achieving sustainable development goals by creating an adequate infrastructure, through industrialization and innovation. This indicator 
shows to what extent the environmental costs of the system's economic development are justified.

The methodological framework that underpins our study comprises the methods permitting the analysis of localization of territories with different environmental problems and degrees of pollution, in particular cartographic analysis, which helps visualize the position of territories of different types in relation to each other, and spatial correlation methods (Moran's statistics).

It should be noted that spatial modeling is often used to analyze the differences between the environmental parameters of different territories, although in most studies, it is applied to investigate the connection between urbanization and air pollution [12-14]. In our study, we are going to use spatial correlation methods to identify concentration zones, that is, the groups of territories located in proximity to each other with similar values in the given indicator. Thus, we will be able to identify those elements of the country's space whose pressures on the environment have reached critical levels and compare the location of the country's economic growth poles with that of the major air pollution hotspots.

Our research methodology relies on the calculation of global (1) and local (2) Moran's statistics.

$$
I=\frac{n \sum_{i=1}^{n} \sum_{j=1}^{n} w_{i j}\left(x_{i}-\bar{x}\right)\left(x_{j}-\bar{x}\right)}{S_{0} \sum_{i=1}^{n}\left(x_{i}-\bar{x}\right)^{2}},
$$

where $I$ is Global Moran's I; $x$ is the parameter of interest; $S_{0}$ is the sum of all spatial weights $\left(\mathrm{S}_{0}=\sum \mathrm{i}=1 \sum \mathrm{j}=1 \mathrm{w}_{\mathrm{ij}}\right)$; and $n$ is the number of territories.

$$
I_{L_{i}}=z_{i} \sum w_{i j} z_{j}
$$

where $I_{L_{i}}$ is Local Moran's I of the ith territory; $w_{i j}$ is the standardized distance between the ith and jth territories; $z_{i}$ and $z_{j}$ are the standardized values of the given parameter for the ith and jth territories.

Global Moran's I measures the spatial correlation - the dependence between the values in the given parameter and the values in the same parameter observed at neighboring locations. Local Moran's I can be used to analyze the relationship between the values observed at a specific location and the values observed at the neighbouring locations included into the dataset. We use Local Moran's I to select the territories that have the strongest correlations with their neighbours. Moreover, such calculations can be used for clustering to identify the leaders in the given parameter and the areas of concentration that they form with each other and other nearby locations. The regions are grouped depending on the ratio of standardized values for these locations in the given indicator to values of the spatial factor. Afterwards, we considered only the territories for which the local Moran's Is were significant $\left(\left|I_{L_{i}}\right| \geq\right.$ $0,001)$.

\section{Results}

In recent years, there has been a decline in the volume of emissions from stationary sources in Russia (Fig.1, a). Interestingly, this decline was achieved when large enterprises made some adjustments to their emissions management policies rather than curtailed their scale of production and economic activity (Fig.1, b). 


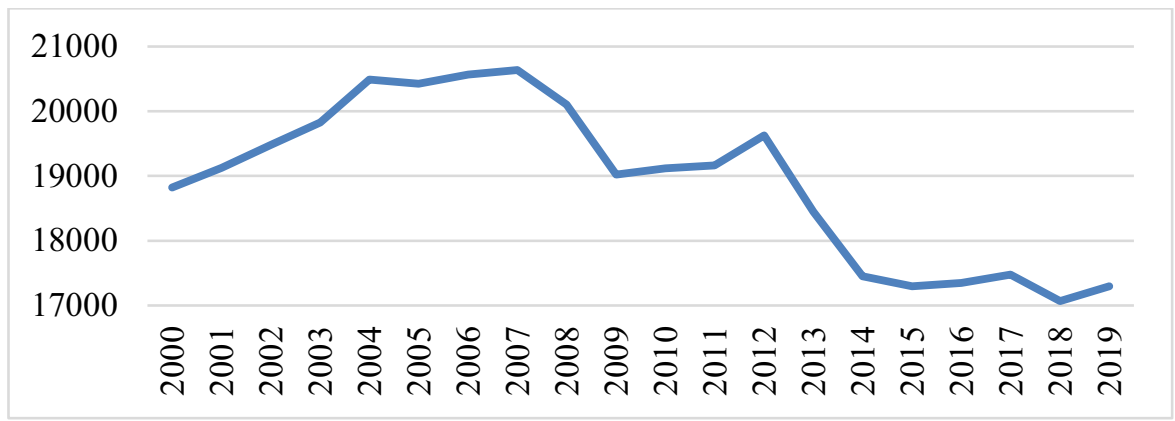

a) total (ths tons).

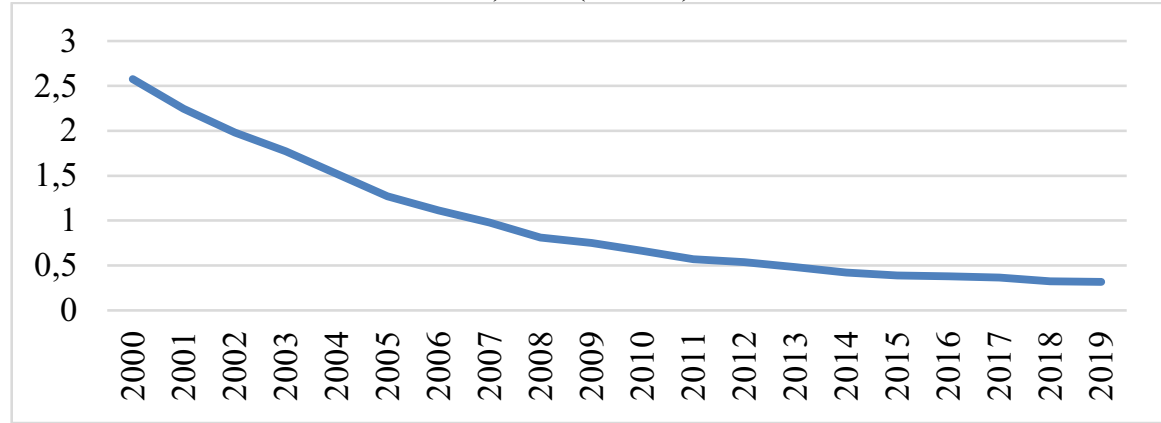

b) per unit of added value (tons per mln rbs).

Fig. 1. Atmospheric emissions from stationary sources in Russia (Compiled by using the data of the Federal State Statistics Service. URL: https://eng.gks.ru/).

At the same time the dynamics of the situation (and the nature of the current trends) is characterized by significant spatial heterogeneity. Despite the fact that the positive trends regarding the volume of emissions in the majority of Russian regions are close to the national average, the extent of air pollution in some parts of the country (e.g. Omsk and Krasnoyarsk regions) does not alter significantly with time and in some regions air pollution tends to increase (Krasnodar and Moscow regions). The most significant growth in atmospheric emissions is found in Krasnodar region: in the last 15 years this figure has risen almost 8 times. To a certain extent, such situation is caused by the growing scale of production. The region's economic potential grows slower in comparison with the fast-increasing environmental pressures from economic development. Nevertheless, the leader in terms of emissions of atmospheric pollutants is not Krasnodar region, but Krasnoyarsk region, which comes first in the ranking of the most polluted Russian regions. This situation may stem from Krasnoyarsk region's industrial specialization (it has plenty of large metallurgical enterprises and coal-fired power stations, which are a major source of emissions) that has a particularly heavy toll on its environment.

Visualization of the way regions with the highest levels of atmospheric emissions are positioned in relation to each other (see Fig.2) shows that the most severe air pollution is observed in Siberia and the Urals (these zones are indicated by a circle).

At the top of the pollution ranking are industrial territories with an abundance of largescale manufacturing facilities in need of modernization. Although a significant number of old industrial regions are also concentrated in the central part of the country (left part of the map), the extent of their environmental pressure is insignificant (mostly because their economies are not very productive). 


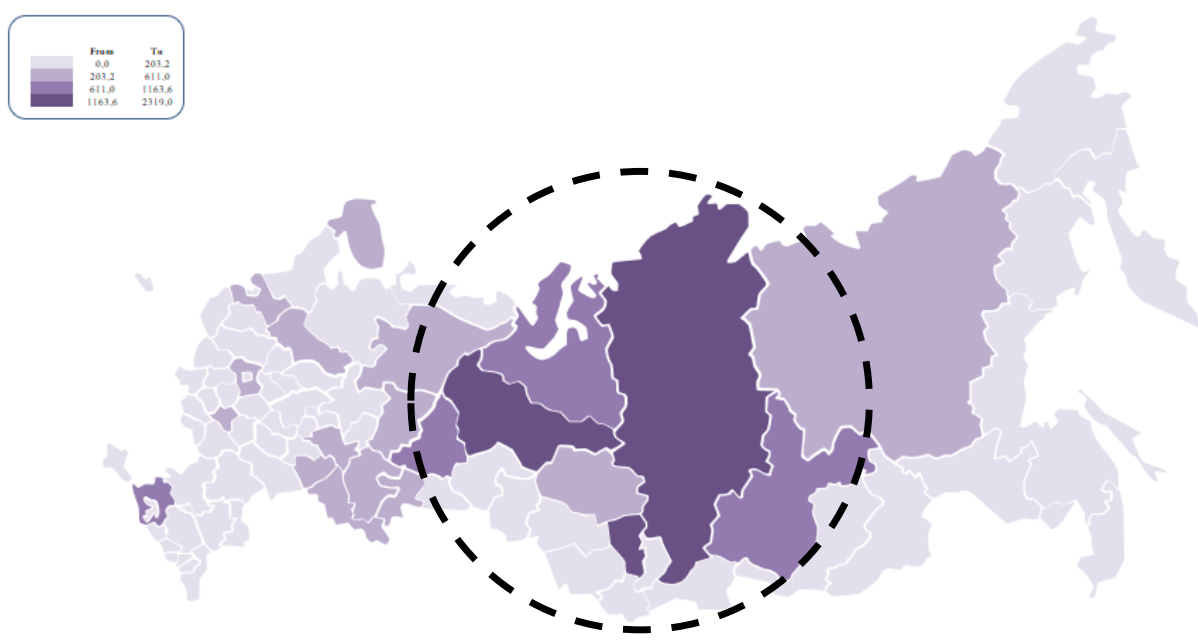

Fig. 2. Localization of the Russian regions with the highest level of air pollution from stationary sources, 2018 (ths tons).

A darker shade is used to indicate the regions with the highest levels of air pollution.

The difference between the emissions per unit of value added in different regions is quite telling (Fig.3). The most alarming levels (high emissions volume) are observed in the most polluted regions. These include Krasnoyarsk region and its neighbour Kemerovo region, which are the leaders in terms of air pollution, as well as Krasnodar region, which is ahead of other Russian regions in terms of the rates of emissions growth. Nevertheless, there is one more zone, which is clearly visible on the map, that may be a cause of concern (on the map it is shown with a dashed line). This zone encompasses some of the territories in the Urals (Sverdlovsk, Chelyabinsk, and Orenburg regions, the Republic of Bashkortostan) whose environmental pressures from economic activities far exceed those in the majority of Russian regions.

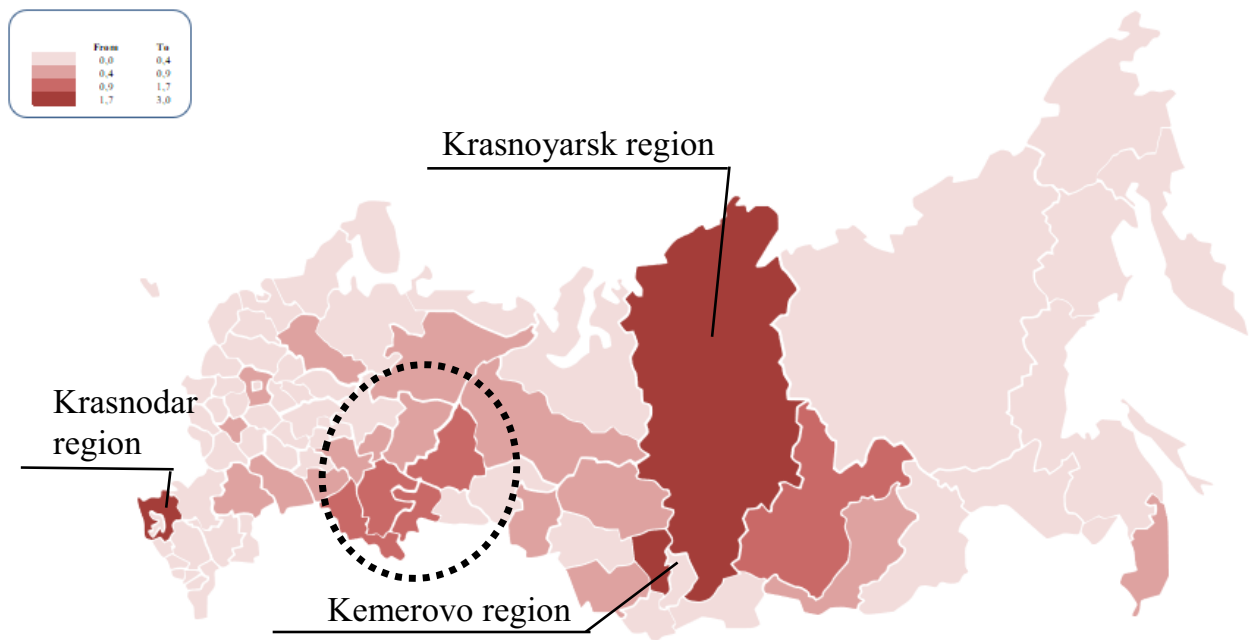

Fig. 3. Localization of the Russian regions with high volumes of emissions from stationary sources per unit of value added, 2018 (tons per million rbs).

The regions with the highest volume of emissions per unit of value added are shown with a darker shade. 
If we look at those groups of regions that we have identified in the two given indicators (the volume of emissions from stationary sources and the volume of emissions per unit of value added), we will see that they do not completely coincide with each other (see Fig. 2 and 3), although the general contour of the most polluted zones in Figures 2 and 3 does not differ significantly. This may point to the fact that Russian regions do not always have to pay the price of environmental pollution for rapid economic development. On the other hand, the majority of territories suffering from severe air pollution are ahead of other regions in such indicator as the volume of emissions per unit of value added.

The calculation of Global Moran's I for the indicator 'Volume of Atmospheric Emissions from Stationary Sources' has shown a positive spatial correlation - observation values for neighbouring territories are close to each other (Global Moran's I is 0.057 , its calculated value exceeds the expected value). Thus, we are dealing with the concentration of regions with similar values in this indicator in one zone (or several zones). Figure 4 illustrates the spatial correlation between the regions in terms of atmospheric emissions. It should be noted that the list of extrema of the given system does not necessarily coincide with the list of regions leading on this indicator: in this case, along with the indicator values, we need to take into account the territories' proximity to other regions with similar emissions levels and the scale of the correlation (this can be estimated with the help of Local Moran's I). The latter parameter is also taken into consideration to identify those regions that have close connections with extrema territories.
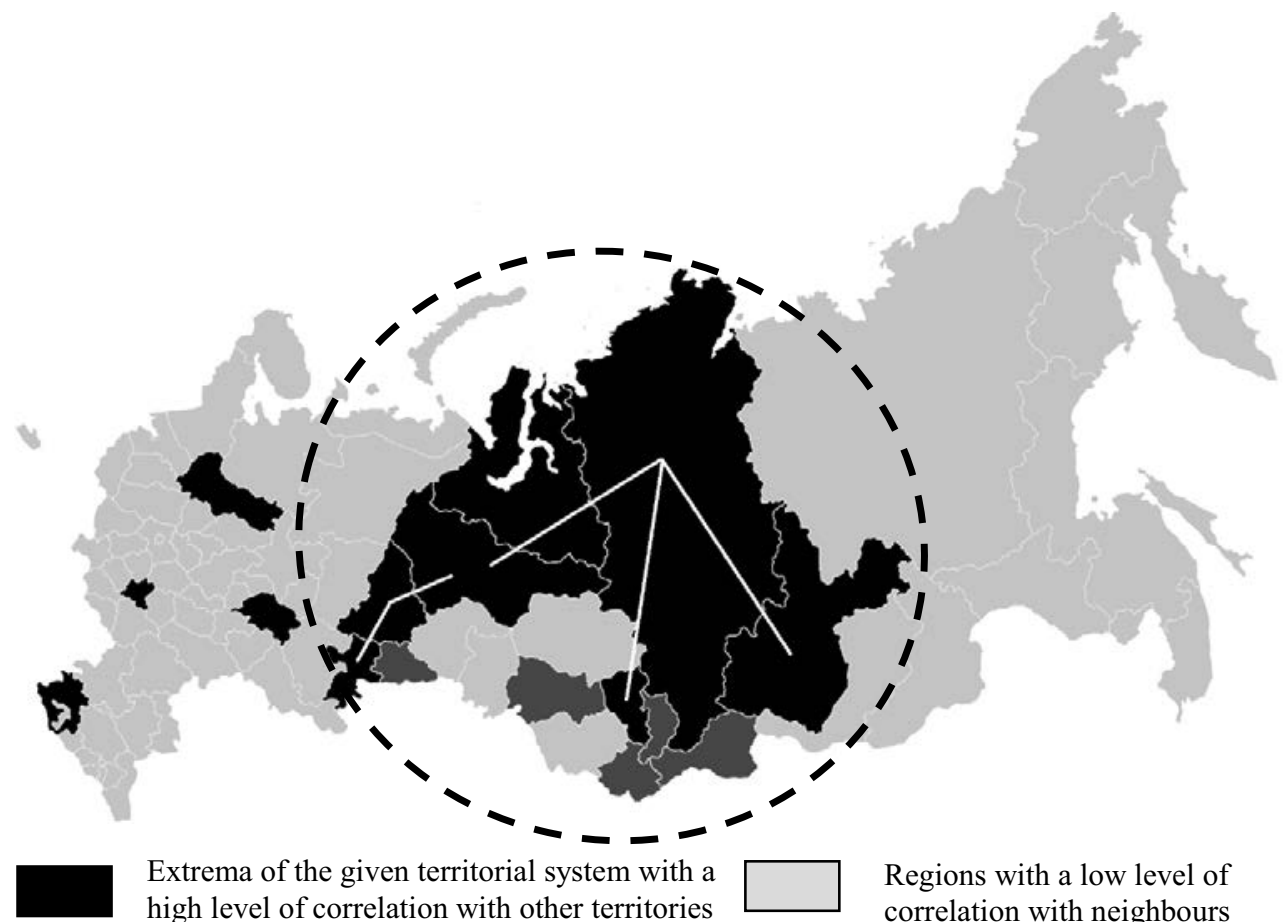

Extrema of the given territorial system with a high level of correlation with other territories

Regions with a low level of correlation with neighbours

Regions with a high level of correlation with neighbouring extrema (direct correlation)

Strongest interterritorial connections (high correlation)

Fig. 4. Spatial correlations between Russian regions in the indicator 'Volume of Atmospheric Emissions from Stationary Sources'. 
Spatial autocorrelation analysis of GRP data also brought to light a similarity of values for the neighbouring territories (the observed Moran's I insignificantly exceeds the expected value). A relatively small value of the index (-0.003) points to the existence of a large extremum, exceeding other regions in this indicator and located quite far from the other leading territories (Moscow and Moscow region). The regions located near this extremum share a strong inverse correlation. If we look at the spatial correlation parameters, we will be able to identify one more area with a sufficiently strong economic growth. Interestingly, specific components of this growth reflected in the indicator 'Gross Regional Product' have a low level of correlation with other territories' values in this indicator (Fig. 5).

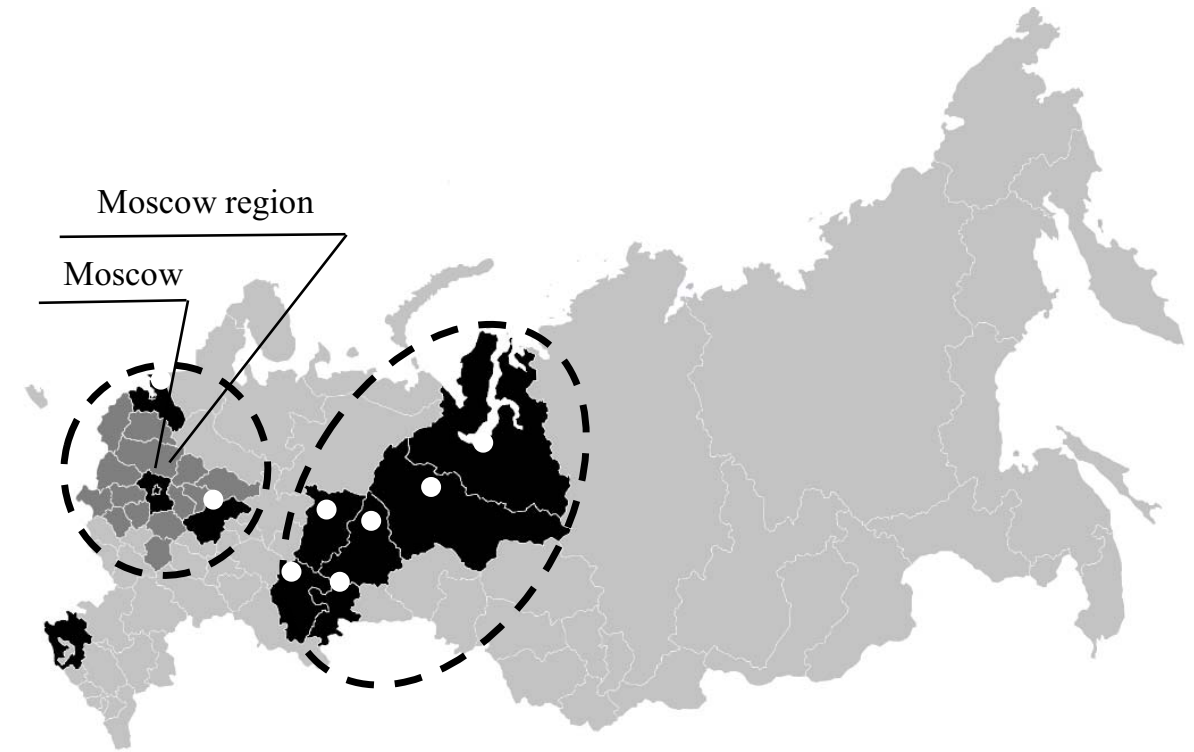

Extrema of the given territorial system

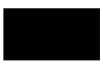
with a high level of correlation with other territories

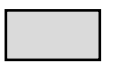

Regions with a low level of correlation with neighbours

Regions with a high level of correlation with neighbouring extrema (inverse relationships)

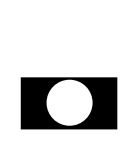

Extrema of the given territorial system with a low level of correlation with other territories and located near each other

Fig. 5. Spatial correlations between Russian regions in the indicator 'Gross Regional Product'.

Analysis of the areas of extrema concentration in the two given systems provides us with a better understanding of how the most polluted areas are localized and how pollution correlates with economic development. Comparison of these areas confirms our previous conclusion that the organization patterns of the country's environmental and economic space do not always coincide.

The analysis of the spatial correlation between the regions in the parameter 'Volume of Atmospheric Emissions from Stationary Sources per Unit of Value Added' (Fig.6) has revealed the regions with the most severe air pollution, which is not compensated for by their significant economic growth. First and foremost, these are Siberian regions (in Fig.6 this group of regions is indicated by a darker shade and is enclosed in a circle). Ural regions (detected as yet another zone struggling with air pollution in Figure 3) did not qualify as the most polluted territories: despite relatively high values in the given parameter, they have a 
low level of correlation with other territories, which means that the situation in the Urals is not as critical as in Siberia.

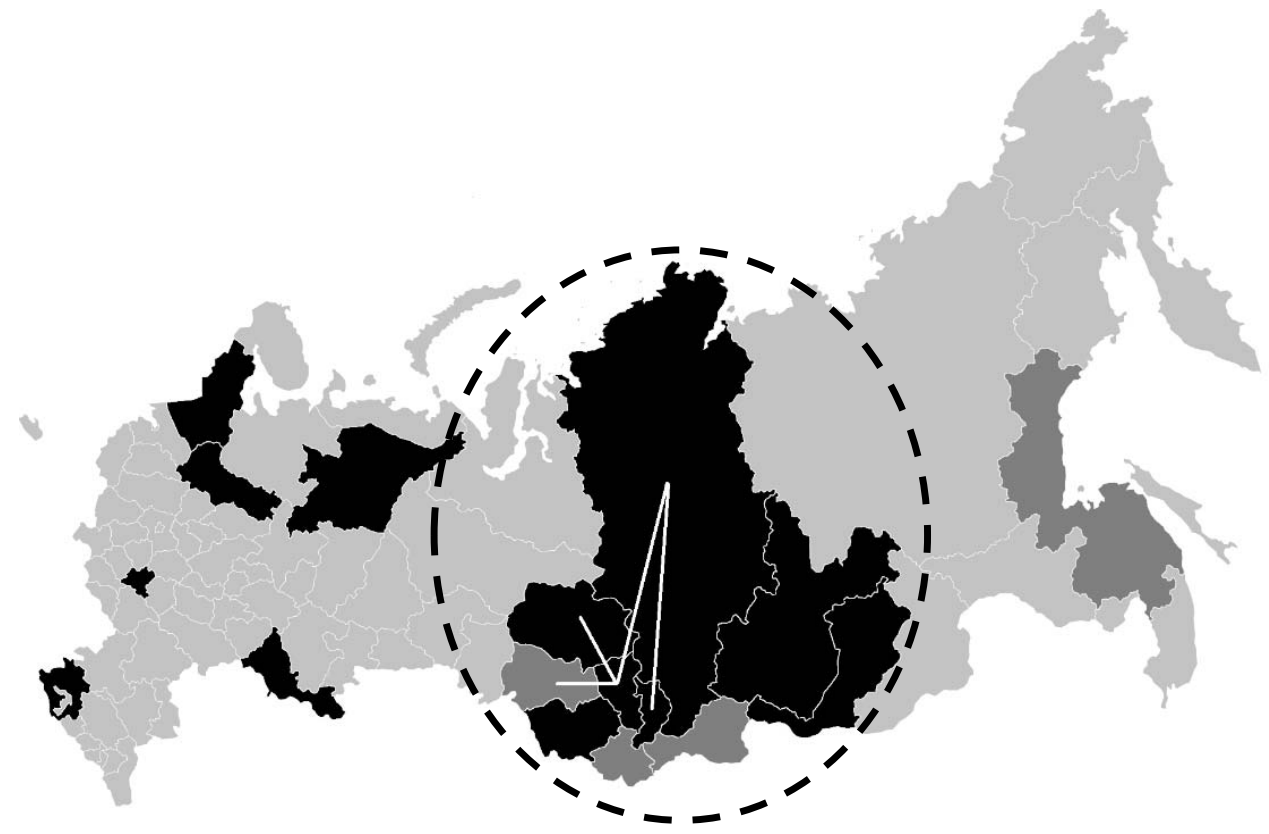

Extrema of the given territorial system with a high level of correlation with other territories

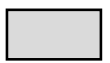

Regions with a low level of correlation with neighbours

Regions with a high level of correlation with neighbouring extrema (direct correlation)

Strongest interterritorial connections (high correlation)

Fig. 6. Spatial correlations between the Russian regions in the indicator 'Volume of Atmospheric Emissions from Stationary Sources per Unit of Value Added'.

The situation in some territories identified as extrema and having a high degree of correlation with other regions (in Fig.6 these regions are shown with the black colour and are located outside of the circle) is also far from perfect. However, as in the case of the Urals, in these regions, air pollution has not reached the critical level yet, largely due to the fact that there are no other extrema regions in the vicinity.

\section{Discussion}

In concluding the description of our findings, we would like to highlight their most salient outcomes and emphasize the most important aspects.

First, our analysis has brought to light those elements of the country's environmental space that suffer from the worst air pollution (regions of Siberia). However, we intended not only to identify the most polluted areas (these are usually at the top of such rankings as the Air Quality and Pollution City Ranking (https://www.iqair.com/world-air-quality-ranking)), but also to find zones of their concentration, where separate elements share spatial correlations. Such zones pose the biggest threat to the achievement of environmental sustainability goals. Territorial systems sharing similar features and located in proximity to 
each other generally have a more powerful effect on the environment as their concentration increases their individual impact.

Second, localization of the most efficient economic centres does not always coincide with the localization of the hotspots of industrial pollution. This result complements the already existing evidence of the direct connection between the level of atmospheric emissions and economic growth. There is no doubt that at a certain stage, economic development starts to place increasing anthropogenic pressure on all elements of the ecosystem. Nevertheless, this does not mean that the emergence of new industries that have detrimental effects on the environment in this or that region will boost economic growth or, on the contrary, that GRP growth is mostly determined by enterprises producing air pollutants. The question as to whether it is possible to decouple economic growth from environmental impacts and thus make it more environmentally sustainable is widely discussed nowadays due to the rise of innovative 'green' technologies permitting high-tech and zero-waste manufacturing. Meanwhile, the share of the so-called 'dirty' industries in economy tends to decrease.

Overall, we have demonstrated that the application of spatial analysis (spatial modeling methods combined with mapping) can help us reveal a number of otherwise hidden aspects and thus significantly complement the picture we can obtain by applying other methods, such as the analysis of the localization of territories of different types, their position in relation to each other and the links between them. Our study has focused on several issues from a wide range of questions, which, in fact, pertain to the problematique of preserving the environment for the sake of present population and future generations. The proposed methodological framework can be applied to study other features of organization of the national environmental space, for example, soil or water pollution, conservation efforts, etc. It should be noted that the focus on spatial aspects does not exclude other important aspects of environmentally sustainable economic development such as factor analysis of environmental pollution. It is, therefore, highly recommended to combine the application of the proposed approach and the findings based upon it with other research tools.

\section{Conclusion}

Implementation of sustainable development goals is fraught with difficulties. The problems different countries and regions face in their attempts to balance their economic, social and environmental priorities of sustainable development are of different nature and complexity. In the light of the above, it would be difficult, if not impossible, to find a unified approach to addressing these problems in order to achieve some kind of a universal goal shared by the whole world community. Therefore, analysis of the role played by the spatial aspects of this process becomes a pertinent task.

Our study analyzes the environmental aspects of national spatial organization by focusing on the case of Russian regions. We detected the 'problem zones', which cause most concern, and, through spatial analysis methods, tested the hypothesis about a direct connection between the anthropogenic pressure on the environment and economic growth. This research takes further previous findings regarding various aspects and conditions involved in the achievement of the goal of environmental sustainability. Thus, our research may be of interest not only to members of the academia but also to specialists of territorial management working on different levels and in different spheres, e.g. specialists of biodiversity, nature conservationists, and so on.

\section{Acknowledgement}

This work is supported by the Russian Science Foundation under grant 20-78-00067. 


\section{References}

1. E.B. Barbier, Environmental Conservation 14(2), 101-110 (1987) DOI: 10.1017/S0376892900011449

2. D.H. Meadows, D.L. Meadows, J. Randers, W.W. Behrens, The limits to growth. A Report for the Club of Rome's project on the predicament of mankind (Universe book, New York, 1972)

3. Z. Ahmed, M.M. Asghar, M.N. Malik, K. Nawaz, Resources policy 67 (2020) DOI: 10.1016/j.resourpol.2020.101677

4. K. Danish, Z. Wang, Sustainable Cities and Society 49 (2019) DOI: 10.1016/j.scs.2019.101626

5. V.G.R.C. Govindaraju, C.F. , Applied Energy 104, 310-318 (2013) DOI: 10.1016/j.apenergy.2012.10.042

6. S.T. Hassan, E. Xia, N.H. Khan, S.M.A. Shah, Environmental Science and Pollution Research 26(3), 2929-2938 (2019) DOI: 10.1007/s11356-018-3803-3

7. M. Yi, Y. Wang, M. Sheng, B. Sharp, Y. Zhang, Ecological Economics 169 (2020) DOI: 10.1016/j.ecolecon.2019.106533

8. L.-O. Wang, H. Wu, Y. Hao, Structural Change and Economic Dynamics 54, 267-281 (2020) DOI: 10.1016/j.strueco.2020.05.006

9. M. Shahbaz, N. Khraief, M.M.B. Jemaa, Renewable and Sustainable Energy Reviews 51, 89-100 (2015) DOI: 10.1016/j.rser.2015.06.014

10. E.A. Tarkhanova, E.L. Chizhevskaya, A.V. Fricler, N.A. Baburina, S.V. Firtseva, Entrepreneurship and Sustainability Issues 8(2), 649-661 (2020) DOI: 10.9770/jesi.2020.8.2(39)

11. P. Moran, Journal of the Royal Statistical Society 10(2), 243-251 (1948)

12. M.C. Jung, J. Park, S. Kim, Sustainability 11(2) (2019) DOI: 10.3390/su11020476

13. J. Chen, L. Wang, Y. Li, Journal of Environmental Management 273 (2020) DOI: 10.1016/j.jenvman.2020.111123

14. C. Fang, H. Liu, G. Li, D. Sun, Z. Miao, Sustainability 7(11), 15570-15592 (2015) DOI: $10.3390 / \mathrm{su} 71115570$ 